\title{
“Keep moving forward. LEFT RIGHT LEFT": A Critical Metaphor Analysis and Addressivity Analysis of Personal and Professional Obesity Blogs
}

\author{
Dimitrinka Atanasova
}

\begin{abstract}
Blogs are a valuable information source for health researchers and individuals managing chronic conditions such as obesity. Yet, there is little research on obesity blogs with existing studies focusing on specific obesity-related issues or examining blogging as a weight loss tool. Even less is known about how the overall obesity experience is conceptualised by blogging individuals and medical experts (particularly via metaphor - a device that aids discussions of sensitive issues) or the addressivity and self-presentation strategies employed on an interactive platform which affords tailored identity construction. This study analysed 343 posts from six (personal and professional) obesity blogs using critical metaphor analysis and addressivity analysis. The preferred source domain of metaphors in both blog types was Journey - with potentially positive implications for doctor-patient communication. Across blogs, Journey metaphors were recruited to highlight similar aspects of obesity in ways that challenged the mainstream before-after weight loss narrative. In personal blogs, Journey metaphors were employed to present the authors as travellers; in professional blogs, as guides. Metaphors thus contributed to self-presentations consistent with traditional views of the doctor-patient relationship. Finally, while individuals used various addressivity strategies, medical experts preferred those that project professionalism.
\end{abstract}

Keywords: addressivity; blogging; interactivity; metaphor; obesity; self-presentation

\section{Highlights}

- Journey metaphors dominated both personal and professional blogs

- These metaphors were recruited to challenge mainstream weight-loss narratives

- Individuals presented themselves as travellers, medical experts as guides

- Individuals employed a range of addressivity strategies to engage readers

- Medical experts used addressivity strategies that convey professionalism

\subsection{Introduction}

People increasingly seek health-related information online and those of us living with chronic conditions, of which obesity - "excessive fat accumulation that may impair health" (World Health Organization, 2016) - is an example, are more likely to do so than other internet users (Pew Research Center, 2014). Blogs in particular are considered "uniquely suited" to the needs of chronic disease sufferers (Pew Research Center, 2014). As a source of naturally occurring data that is not influenced by the investigator's presence, blogs are also regarded as a promising data source for health research (Eastham, 2011). Yet, with few exceptions, obesity blogs have been understudied. Lingetun and colleagues (2017: 65) analysed obese women's blogs to understand how they conceptualised pregnancy and concluded that pregnancy was used as "an excuse" for being obese. Leggatt-Cook and Chamberlain (2012) studied women's blogs explicitly stating that blogging was used to aid weight loss. The analysis examined the therapeutic relationship between bloggers and readers established through commenting. As bloggers documented their "weight-loss journey[s]," readers supported them by responding that they are, indeed, on a "journey to a most amazing place" (Leggatt-Cook \& Chamberlain, 2012: 966-972). However, readers were occasionally critical of bloggers' accounts of food consumption and physical activity and thus, held them accountable. 
Such research holds valuable insights concerning specific obesity-related issues and blogging as a weight loss tool. Yet, it tells us little about how individuals and medical experts conceptualise the overall obesity experience (particularly via metaphor - a device that aids discussions of sensitive issues) or the addressivity and self-presentation strategies employed on an interactive platform which affords tailored identity construction. The interactivity of blogs, specifically commenting, has received much attention in general (Bronstein, 2013; Karlsson, 2007) and, as demonstrated by the above examples, it has also been studied in obesity blogs (see Leggatt-Cook \& Chamberlain, 2012). Commenting though is not the only way in which blogs can be interactive. Bloggers use a range of more or less obvious linguistic devices to make readers feel addressed (Myers, 2010a). Also, instead of interactivity, some readers have attributed their continued engagement with blogs to "a language of affect" (Karlsson, 2007: 151). Affect is closely linked to metaphor, which works by arousing emotions in order to persuade (Charteris-Black, 2004, 2011). Metaphors are not only persuasive devices (Charteris-Black, 2004) - they can also grab and hold readers' attention (Semino, 2008) and they aid discussions of sensitive issues (Semino et al, 2015). As quotations from previous research show (see Leggatt-Cook \& Chamberlain, 2012), metaphors are common in obesity blogs, which adds further support to the argument that research into their role in conceptualising obesity is much needed.

The following sub-sections detail the approach to blogs, interactivity, metaphor and self-presentation adopted in this study and explain how metaphor and interactivity can contribute to self-presentation on blogs.

\subsubsection{Blogs}

Blogs are websites on which posts are regularly written and displayed in reverse chronological order (Rowse, 2005). They can be divided into "filter blogs" - for curating and reflecting on external content such as research articles, "knowledge-logs" - to present information and observations about a topic, "personal journals" - dedicated to the experiences, internal states and reflections of the blog author and "mixed blogs" - which combine the features of several of the above types (Herring et al, 2004). While women have emerged as the main producers of "personal journals," men mostly write "filter blogs," "knowledge-logs" and "mixed blogs" (Herring et al, 2004). "Personal journals" were initially severely understudied (Herring et al, 2004), but are now recognised as a platform where dominant discourses can be challenged and alternative ones advanced (Jaborooty \& Baker, 2017).

In a health context, "personal journals" offer an opportunity to review whether and how mainstream health and illness narratives are reworked online (Page, 2012). Advertisements, health magazine articles, television infomercials and news reports typically have a before-after narrative structure, which presents fatness as temporary and weight loss efforts as following a linear trajectory leading to weight loss (Ata \& Thompson, 2010; Blaine \& McElroy, 2002; Geier et al, 2003; Maor, 2014; Puhl \& Heuer, 2009). These narratives derive from the wider before-after framework prominent in Western societies, which sees modernity as unidirectional progression from the past to a desired future (Levy-Navarro, 2009; Maor, 2014). The straightforward exit from the "before" category that such narratives suggest is not an experience shared by many. Of people who lose a significant amount of weight through dieting, $95 \%$ regain it within a few years (Heatherton et al, 1997). Unlike other online genres (such as discussion forums), "personal journals" are not necessarily linked to a contextual frame of an organisation's home page that creates expectations about content (Page, 2012; Seale et al, 2006). While influenced by diary and autobiography writing, "personal journals" are also less retrospective and are written in discontinuous, episodic posts (Page, 2012). This all suggests that they can offer a platform on which alternative, perhaps more fluctuating versions of the weight loss narrative can be expressed. 


\subsubsection{Interactivity}

Blogs are frequently described as "distinctly social" (Lomborg, 2014: 15). Much like the telephone, they are the direct facilitators of interaction, but unlike other social media (for example Facebook, where users can connect with classmates with whom they have had offline contact) interaction on blogs does not build on pre-established relationships. Instead, interactions occur between strangers whose interests overlap. Given the lack of shared common ground from the outset (Lomborg, 2014), it can be argued that interactivity - that is, whether readers are addressed on what constitutes a dialogical platform (Page, 2012) - is especially important.

The most obvious form of interactivity is when blog authors enable commenting and respond to readers' contributions. Additionally, bloggers may draw on a range of addressivity devices to engage the reader (Myers, 2010a). The use of such devices can help produce "the right audience," reassuring readers "that it might be completely reasonable to interact with this total stranger" (Myers, 2010a: 93). Addressivity strategies range from the more explicit (using the pronoun "you," directly naming the addressee(s), posing questions and issuing directives) to the less explicit (for example, requiring readers to draw inferences that can only be made with specific shared knowledge) (Myers, 2010a). The pronoun "you" has emerged as the most common addressivity strategy in blogs (Myers, 2010a). "You" is prototypically used to refer to the addressee(s) in an interaction, but may also be impersonal when it refers to people in general ("you" in such cases can be replaced with "one") (Myers \& Lampropoulou, 2012).

\subsubsection{Metaphor}

Curiously, some readers have attributed their continued engagement with blogs not to interactivity, but to "a language of affect" (Karlsson, 2007: 151). Affect is closely linked to metaphor - defined as talking and potentially thinking about one thing in terms of another (Semino, 2008). Metaphor, as Charteris-Black $(2004,2011)$ wrote, works by arousing emotions in order to persuade. In addition to the power to persuade, metaphor can grab and hold readers' attention (Semino, 2008) and has been shown to aid the discussion of sensitive issues (Semino et al, 2015). Understanding what metaphors are preferred by specific groups of people (such as patients and medical experts) is significant, as different metaphors frame issues differently. When discussing their findings about metaphors in cancer narratives, Semino and colleagues (2015) found that War metaphors conceptualised the illness as an enemy, presented patients as fighters and associated not recovering with defeat. In contrast, Journey metaphors framed cancer as a travel companion and did not suggest that not recovering amounted to personal failure (Semino et al, 2015). While both Journey and War metaphors conferred an active role to patients, the emphasis in Journey metaphors was on perseverance, in War metaphors on violent action at any cost (Semino et al, 2015).

\subsubsection{Self-presentation}

The above examples suggest that metaphors can additionally function as tools for selfpresentation - a major concern of bloggers who need to position themselves on "a crowded terrain" (Myers, 2010b: 264). Goffman (1959) who described life as a stage and all individuals as performers also spoke of "back stage[s]" and "front stage[s]." In the "front stage," people aim to present an idealised version of who they are according to a specific role (a patient, a medical expert) (Hogan, 2010). Metaphors can be enlisted in such strategic identity management to purposefully "give" (rather than accidentally "give off") an impression (Goffman, 1959). Goffman's (1959) "front" and "back stage[s]" are useful for understanding offline as well as online self-presentations (e.g. Koteyko \& Hunt, 2016). Some researchers have even suggested that online media can be classified as inherently "front" or "back stage" 
depending on the degree of control over access that authors have vis-à-vis an audience (Hogan, 2010). Blogs being freely accessible to readers qualify as "front stage" platforms on which authors may wish to construct idealised versions of their selves according to specific roles (in contrast to "back stage" online media such as Facebook, where the audience of posts can be controlled via privacy settings).

But it is not only metaphors that contribute to self-presentation. As mentioned, the pronoun "you" (which can be personal or impersonal) is the most common addressivity strategy in blogs. The impersonal "you" is often recruited to display distance and objectivity - attributes associated with professionalism (Stirling \& Manderson, 2011). Depending on the ideal identity that one may want to construct on a "front stage" platform like blogs, giving an impression of objectivity and therefore professionalism may be more (or less) important. It may be more important for professionals even if they blog in a personal capacity and not on an organisational blog (Greenland, 2013). For example, research of politicians who blog in a personal capacity has shown that they actively crafted a professional identity by using formal prose and covering topics of political interest (Nilsson, 2012).

Against this background, the present study analysed blogs authored by individuals (referred to as personal blogs) and by medical experts (hereafter professional blogs). The analysis was guided by two principal research questions (RQs):

RQ1: What metaphors did the bloggers employ to frame obesity (and how)?

RQ2: How did the bloggers address the audience in the instances of metaphor use?

The next section describes the sample and method, including ethical considerations. Following this, the results are presented and discussed. The paper concludes with a summary of key findings, limitations and future directions.

\subsection{Materials and Methods 1.2.1 Sample}

A recent ranking by Healthline - one of the largest providers of consumer health information on the web (Roush, 2011) - identified 14 obesity blogs as "the very best" to follow in 2016 on account of their "frequent updates and high quality information" (Schaefer, 2016). Preliminary monitoring of posting activity (the average number of posts shared during each month of 2015) identified several of these blogs as especially actively updated. These are also the blogs analysed in the present study including four blogs authored by individuals ("300 Pounds Down," "Diane Carbonell," "Escape from Obesity" and "The World according to Eggface") and two blogs written by medical experts ("Dr Sharma's Obesity Notes" and "Weighty Matters").

Authorship of personal and professional blogs was gendered, as the former were written by women and the latter by men. Women's higher propensity to blog about first-hand experiences of obesity conforms to wider observations about obesity's gendered nature. Women are significantly more likely to undergo bariatric surgery (Fuchs et al, 2015) and access weight management services (Archibald et al, 2015). This is despite the equal distribution of obesity among men and women in most geographies (Archibald et al, 2015). The disproportionate degree of weight-based discrimination in education, employment and health care experienced by women (Fikkan \& Rothblum, 2012) may explain such tendencies. In a culture that allows for much less deviation from aesthetic ideals for women than it does for men, women may feel more compelled to lose weight by various means and to blog about their experiences. The gendered authorship of personal and professional blogs also corroborates observations regarding the relationship between blog type and gender. The analysed personal 
blogs resembled "personal journals" - a type associated with women (Herring et al, 2004). The professional blogs, where posts provided personal reflections on obesity-related research articles, resembled the "filter" blogs typically dominated by men (Herring et al, 2004).

The timeframe for analysis was 1 January 2015 - 31 December 2015, as the Healthline ranking from which the blogs were selected focused on 2015 posting activity. Not all blog posts dealt with obesity (unrelated topics included product giveaways, event announcements, job openings). After such posts and guest posts (found exclusively in professional blogs) were discarded, the total number of relevant obesity-related posts was 343 (190 from personal, 153 from professional blogs).

\subsubsection{Method}

This study followed the three steps of Charteris-Black's (2004) critical metaphor analysis: identification, interpretation and explanation. Within the identification step, the entire blog posts (including blog titles) were read to isolate keywords and candidate metaphors, referring to whole linguistic expressions that are metaphorically used. When deciding whether a word or expression had been used metaphorically it was considered whether it has a more basic, concrete meaning in other contexts (Pragglejaz Group, 2007). Sections containing a metaphor keyword or a candidate metaphor were systematically lifted from each blog post and entered into a spreadsheet, the rows of which represented the blog posts and the columns recorded the instances (and frequencies) of different metaphor keywords and candidate metaphors. At the interpretation step, the recorded sections of text were read to identify "conceptual metaphors" and "conceptual keys" (Charteris-Black, 2004: 38). Analysis within the explanation step elaborated: (1) the specific aspects of obesity that a metaphor was used to conceptualise (for example, weight loss); and (2) whether the blog author employed addressivity strategies (which ones and how) to make readers feel talked to. Addressivity analysis involved coding indications of addressing an audience in the instances of metaphor use (such as uses of "you," direct naming of the addressee(s)) (see Myers, 2010a).

\subsubsection{Ethics}

The studied blogs can be described as public data which does not require formal informed consent - they may be personal, but not private (Hookway, 2008). Their owners (including of the personal blogs), qualify as public figures similarly to journalists. Some of them, like "Diane Carbonell" are book authors and blogs bear their names. Bloggers are thus credited when direct quotes from their posts are used in this paper. Yet, since obesity is a sensitive issue, the ethical treatment of personal blogs was of particular concern here. Although their authors may not perceive posts as private (as, for example, suggested by the instructions they gave on referencing their blog posts), they may not expect research attention. These are individuals who, in contrast to the blogging medical experts, may not have been involved in academic research. The authors of personal blogs were therefore contacted (by email or contact form) to explain the study aims. Ethical approval was granted by [institution name after review].

\subsection{Results and Discussion}

Posts on personal blogs were, on average, longer (945 words) than posts on professional blogs (375 words). The authors of "300 Pounds Down" and "Weighty Matters" wrote the longest and shortest blog posts (2,109 and 363 words on average, respectively). Personal blogs were more likely than professional ones to contain metaphors (see Table 1) - a tendency observed in other studies of metaphor use across lay and professional narratives (Semino et al, 2015). As examples of "filter" blogs, professional blogs often featured extended block quotes from the original texts of research articles and the commentary offered by the blog authors was devoid of figurative language. In "The World according to Eggface" where metaphor use was the 
lowest among the personal blogs, many posts were of the type "Post weight loss surgery menus: A day in my pouch." Such posts documented meals and offered recipes.

Table 1 Blog posts in total and containing metaphors

\begin{tabular}{|l|l|l|}
\hline Blog Name & Obesity-related Posts & $\begin{array}{l}\text { Obesity-related Posts } \\
\text { with Metaphors }\end{array}$ \\
\hline "300 Pounds Down" & 40 & $30(75.0 \%)$ \\
\hline "Diane Carbonell" & 32 & $14(43.8 \%)$ \\
\hline "Escape from Obesity" & 71 & $30(42.3 \%)$ \\
\hline "The World according to Eggface" & 47 & $10(38.9 \%)$ \\
\hline Total in personal blogs & $\mathbf{1 9 0}$ & $\mathbf{8 4 ( 4 4 . 2 \% )}$ \\
\hline "Dr Sharma's Obesity Notes" & 113 & $15(13.3 \%)$ \\
\hline "Weighty Matters" & 40 & $16(40.0 \%)$ \\
\hline Total in professional blogs & $\mathbf{1 5 3}$ & $\mathbf{3 1 ( 2 0 . 3 \% )}$ \\
\hline Total & 343 & $115(33.5 \%)$ \\
\hline
\end{tabular}

While War metaphors have been identified as a prime descriptor of obesity in mainstream media (De Brún et al, 2012; Saguy \& Almeling, 2008), the authors of the analysed blogs most frequently recruited Journey metaphors to talk about obesity. This can be seen as affirmation of blogs' potential to offer a platform where narratives that are alternative to the mainstream can surface. The emergence of Journey as the favoured metaphor domain across personal and professional blogs has potentially positive implications for doctor-patient communication as well. Metaphors can help discuss issues that are sensitive in terms of less sensitive ones. Thus, their use can help overcome communicative problems. Equally, metaphor use can lead to miscommunication when different discourse communities, defined as groups of people who have texts and practices in common (Ritchie, 2013), use different metaphors to establish particular ways of thinking about an issue (Demjen et al, 2016). When healthcare professionals and patients use radically different metaphors to conceptualise the same condition, there is the risk that patients' needs and expectations will not be understood and met. Such divergent metaphor use was not the case in the analysed material and hence, the suggested positive implications for doctor-patient communication.

Yet, drawing on the same metaphor domain does not guarantee that the same aspects of an issue will be foregrounded. A metaphor may be used by different discourse communities to fulfil different functions. The remaining part of this section considers: the functions which Journey metaphors fulfilled in personal and professional blogs; the aspects of obesity that they highlighted; and whether bloggers addressed the audience in the instances of Journey metaphor use. As personal blogs were richer in metaphors and employed a wider range of addressivity strategies, they are discussed first. Several points to note include that: the direct quotes presented below are indicative, not exhaustive examples; underlining signifies metaphorical expressions, bold the use of impersonal "you," italics of personal "you," small capitals indicate conceptual metaphors and initial capitals label metaphors more generally.

\subsubsection{Journey Metaphors and Addressivity in Personal Blogs}

In personal blogs, Journey metaphors fulfilled functions that can be summarised as (1) conceptualising weight loss, (2) conceptualising weight gain and (3) presenting the blog author as a (sometimes lone, reluctant or still on the road) traveller.

When conceptualising weight loss, its trajectory was charted differently than implied by the mainstream before-after narrative (which suggests a linear progression from one stage to another). While such representation may be at odds with the personal weight loss experiences of many people, the absence of narratives of fluctuating trajectories from the mainstream might 
encourage feelings of failure and inadequacy. In this respect, bloggers' narratives made a significant contribution in terms of adding this fluctuating voice of weight loss - "I've gone forward. I've gone backwards" ("300 Pounds Down") - and stressing that the weight loss journey is not necessarily linear - one may take "two steps forward and twelve steps back ("300 Pounds Down"). As the same blogger put it:

I vowed that I would write this blog with honesty. That I would not just be someone who sugar coats everything and only shows themselves in a positive light. But rather I would present my weight loss journey to you in all its twists and turns. ("300 Pounds Down")

Metaphor use in the above example is combined with use of the personal "you" to refer to all the readers of the blog at once. This post is, in fact, a response to a reader's comment criticising the lack of success stories on the blog and is written to clarify the blog's goals to all readers:

All I can offer you is an honest glimpse at who I am. Perhaps I should have waited to tell this story until I too could stand up and speak of mistakes I already made and how I now have arrived. (...) instead I am doing it in real time. I am offering it up to you as it stands." (“300 Pounds Down”)

Bloggers also highlighted what is important on the weight loss journey - to keep moving forward - and they often did this while making extensive use of the personal "you":

If your resolutions were about your health and weight. Here's my PSA Public Service Announcement with some resources to hopefully help you. Know that the first weight loss method selected may not be the one for you. Failure isn't falling down. It's remaining where you have fallen. ("The World according to Eggface")

The idea of stopping hinted in the above quote is a metaphor grounded in physical experience and refers to giving up. Stopping was therefore rejected across all personal blogs as the following two examples will demonstrate. The latter of these examples also employed a directive that called for action - "Keep moving forward. LEFT RIGHT LEFT" - which constitutes another addressivity strategy (Myers, 2010a). Notably, "Keep moving forward. LEFT RIGHT LEFT" was also the title of the post and the expression recurred throughout the body of the post. It was not uncommon for metaphors (combined with addressivity devices) to feature prominently in post titles - possibly, a conscious strategy that bloggers employed as part of their efforts to engage and draw readers in.

I know the hardest part is starting, and the second hardest part is continuing. I know that once I get going and start to catch the vision again, it'll get exciting for me again. ("Escape from Obesity")

Keep moving forward. LEFT RIGHT LEFT. I think something that is important to be aware of during times when we are trying to break bad habits is that any step in the right direction is progress. LEFT RIGHT LEFT. That's the way. One foot in front of the other. One step at a time. ("300 Pounds Down")

The positive evaluation of forward movement apparent in the above examples draws on embodied experience of forward movement as inherently purposeful and on our positive associations with forward motion (Charteris-Black, 2011). A humorous play on this belief can be found in the popular saying: "[y]esterday we were still standing at the edge of the abyss, 
today we've gone a step further" (Reisebrodt, 2010: 6-7). Positive associations with forward movement are particularly strong in politics, where it is always favourably evaluated (Charteris-Black, 2011).

Overall, the Journey metaphor provides a mental representation that allows the various aspects of weight loss to be understood and expressed through embodied experience of movement. If weight loss is a journey, then much like physical journeys it may be long or short, fast or slow. These characteristics of journeys were present in bloggers' accounts:

Sometimes the weight loss journey seems endless doesn't it? Do you feel that way sometimes? (...) The weight loss journey can be a long one, or it can be short, depending on your goals and objectives. ("Diane Carbonell")

This quote exemplifies how individuals mixed addressivity strategies. Here, the pronoun "you" targeting a sub-group of the readership (those who may feel that the weight loss journey is endless) was combined with a question addressed to the same sub-group.

The authors of personal blogs also made the case that, as with physical journeys, travelling on the weight loss journey is possible at varying speeds with different benefits ascribed to different speeds:

I had times during my years of morbid obesity when I started my diet fast and furious and times when I started slowly. A fast start gave me hope that I would be able to finally lose all my weight because I was doing so many things. A slow start involved slowly making changes - baby steps (...) In this post, I wanted to talk to you about why a slow

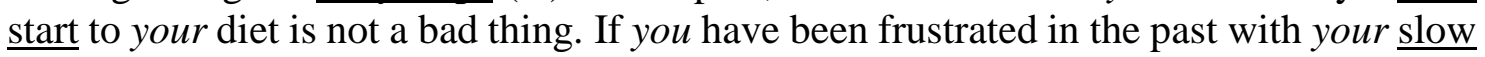
start in weight loss, here are: Five Benefits to Starting Slowly. A slow start can translate into sticking with your diet. ("Diane Carbonell")

This quote is yet another example of using the personal "you" as an addressivity strategy oriented towards a sub-group of the readership (those who may have been frustrated with their slow weight loss).

Whether long or short, fast or slow, the ultimate message in personal blogs was that there is no one-size-fits-all approach to weight loss:

Do you know I've actually found this to be one of the hardest things to do!! To just keep my eyes focused on what works and not be tempted to try other things. I can't tell you how many times I've fallen backwards because I tried to do someone else's plan. We see what works for them and we start to doubt what we are doing. Instead of just marching forward, we look around. We stop marching forward and we start spinning in circles ...but what if their way is better? ("300 Pounds Down")

"You" was used here to address the audience of the blog and the transition from "you" to "we" creates solidarity and encourages a shared feeling. The example further demonstrates the mixing of addressivity strategies common in personal blogs as well as the combining of metaphors to paint a vivid scenario in which one gets distracted on a journey by looking around too much. We can note how the Journey metaphors work in tandem with Seeing metaphors ("keep my eyes focused on what works," "we see what works for them," "we look around"). "Look[ing] around" is part of journeying, but it is also about eyes that see what is in front, behind and all about them. Such co-occurrence of Journey and Seeing metaphors is, in fact, not uncommon in personal narratives (Cameron, 2016). 
Apart from weight loss, the authors of personal blogs also conceptualised weight gain as a journey. These conceptualisations, while infrequent, similarly differed from the mainstream before-after weight loss narrative. In a typical before-after news article, descriptions of a person's past fatness are allocated to the shortest paragraph of the news article, conveying the message that "this epoch" is a relatively brief period, neatly "cordoned-off" from longer periods of what comes "after" (Maor, 2014: 95). Contrary to such before-after narratives which invariably associate the "before" period with unhappiness (Maor, 2014), bloggers' narratives suggested that weight gain can take considerable time and is not entirely negative:

My journey into obesity took 10 years, and although I had great times and memories along the way, being obese was difficult. ("Diane Carbonell")

Finally, bloggers recruited Journey metaphors to present themselves as (sometimes reluctant, lone or still on the road) travellers. Indeed, Journey metaphors are known to be particularly conductive to creating a feeling of optimism and solidarity so that positively evaluated goals can be successfully accomplished (Charteris-Black, 2011). This certainly was how they were used in many of the instances identified in this study such as:

Never let a stumble in the road be the end of the journey. It is easy to get lulled into thinking the scale will always go down but it still goes both ways (...) but we aren't alone (lots of pals on the same road). ("The World according to Eggface")

The purpose of this Monday morning post is to offer you some encouragement and advice on what to do when you make a mistake during your weight loss journey. There may be many times along the way where you falter and stumble. No worries though. A falter or two or three or twenty-five does not mean you will never get there. ("Diane Carbonell")

Journey metaphors were also employed in mutually encouraging greetings such as "for now, goodbye and God bless each of you on your journey" ("Escape from Obesity").

However, Journey metaphors are not by default positive. A study into cancer patients' use of metaphors found that Journey metaphors were used to express empowering and hopeful feelings, but also disempowering experiences and negative emotions. In the case of the latter, cancer patients employed Journey metaphors to convey how they felt like reluctant travellers (Semino et al, 2015). Similar uses were found in the analysed here personal blogs where Journey metaphors were recruited to express unwillingness to travel and frustration with the length of the weight loss journey:

I don't always want to keep moving forward. I don't want to always say no to a box of Donuts and a 2 liter of Coke. And I don't always want to keep pushing through the walls that often go up when the road seems to get longer. ("300 Pounds Down")

Boy does it feel slow sometimes. A pound a week... ("Escape from Obesity")

If there was an awards ceremony for the person with the least enthusiasm for this journey I would have won. (...) How many months and years would it take for me to get there? (“300 Pounds Down”)

The latter quote uses yet a different addressivity strategy - rhetorical questions. Although such questions do not call for an answer from the audience, they promote engagement by calling readers to recognise a shared experience (Myers, 2010a). 
Occasionally, bloggers also identified as lone travellers, but in those instances, the knowledge that journeys tend to be social endeavours rather than solitary ones was used to provide encouragement and to give advice:

All along the way I've had people help me. First my brother. And then later it was others who came along when I needed them. (...) And sometimes for a stretch of the road it seemed like I was shoveling all alone (...) But there's always a turn. There's always someone up ahead. Waiting for their stretch of the road. Waiting to cheer you around that corner. You aren't alone. At least you don't have to be. So reach for the help when you need it. ("300 Pounds Down”)

Finally, if weight loss is a journey and different individuals who are trying to lose weight are travellers, they might be at different points along the road. Those who have "arrived" may serve as "guides" - showing others the way by drawing on their experiential knowledge of success; the ones "on their way" can be travel "companions." Just like in physical journeys, there is good use for both guides and companions. In the following example, a blog author explains the distinction between these types of travellers and identifies as "someone shuffling along":

They now have ARRIVED. They found their way and now stand at the mountain top ready to lead others into the same success. [They] have been down the hard road and found their way. But I am not that person. (“300 Pounds Down”)

\subsubsection{Journey Metaphors and Addressivity in Professional Blogs}

In professional blogs, Journey metaphors fulfilled functions that can be summarised as (1) conceptualising weight loss, (2) conceptualising obesity research and (3) arguing that the declaration of obesity as a chronic disease should be beneficial for obese individuals.

Similarly to how weight loss was presented in personal blogs, medical experts conceptualised weight loss as a journey that is not a straightforward one:

It isn't a straight line. (...) The fact that her loss is anything but a straight line is pretty damn normal because truly nothing in life is a straight line. (...) most folks who are trying to manage their weights tend to give up if the scale doesn't keep going down. Of course had she given up back then she probably wouldn't have gone on to lose 50 more pounds (...) she was reliant on many more restaurant meals and far less organization in her dietary life. When that changed, she started to lose again. ("Weighty Matters")

In this commentary on a patient's weight loss journey, the author challenged the mainstream before-after narrative which suggests that there are separate stages of being with regard to weight and that linear movement from one to the other involves the scales "steadily going down (...) zest for life up" (Atanasova and Koteyko, 2016: 10). As in our physical journeys, we may sometimes wish to stop for a break and ponder how to navigate an obstacle in our path (in the example, the obstacle was reliance on many more restaurant meals linked to the demands of a job). What is, however, important with a view to reaching our desired destination is not stopping. That is, both personal and professional blogs emphasised perseverance.

In what represents a well-established use of the Journey metaphor, it was also employed by the medical experts to conceptualise obesity research:

As for bringing us a step closer to obesity treatments, the study suggests that it may not be easily possible to harness leptin as a treatment for weight loss, as one expected side effect would be an increase in blood pressure. ("Dr Sharma's Obesity Notes") 
Scientific research has often been framed "either as sensational breakthroughs and innovations, or else in terms of steps toward creating new Frankensteins" (Hellsten, 2008: 16). These, in essence, are the two ends of the same metaphorical narrative of science and scientific research as a journey to progress or risky unintended consequences, respectively (Hellsten, 2008).

Finally, on professional blogs Journey metaphors were recruited to argue that the declaration of obesity as a chronic disease should be seen as beneficial to obese individuals:

[F]or the vast majority of people with excess weight, who do in fact face considerable health risks from excess weight, this declaration [by the Canadian Medical Association] will hopefully be a step forward to getting them the help and support they need. ("Dr Sharma's Obesity Notes”)

Such uses are consistent with the widespread use of metaphors of "up" or "forward" movement to evaluate an action positively (FORWARD MOVEMENT IS GOOD, GOOD IS UP); "down" or "backward" movement to make negative evaluations (BAD IS DOWN, BACK IS BAD) (CharterisBlack, 2011; Gregoriou, 2011).

In contrast to how the Journey metaphor was employed in personal blogs, medical experts did not draw on Journey metaphors for explicit self-presentation. In principle though, Journey metaphors can be turned into whole scenarios allowing medical experts to present themselves as "guides." This representation maps well onto official definitions of healthcare professionals' roles and responsibilities and traditional views of the doctor-patient relationship. Consequently, in offline settings, Journey metaphors have been widely used by healthcare professionals to present themselves as guides who help patients select appropriate destinations, overcome obstacles and reach desired outcomes (Tay, 2011).

As the above examples already suggest, addressivity strategies in the instances of Journey metaphor use were much less common in professional blogs. Where such could be identified, the medical experts used impersonal "you" to give general advice directed at a vague audience (with no specific group of audience members being targeted):

Truly, falling happens. Whatever it is you're trying to do with your life - improve health, nurture relationships, parent better, lose weight (...) - the fact of the matter is, sometimes you're going to suck at it, sometimes you're going to fall. Falling down doesn't matter. All that matters is that you get back up. ("Weighty Matters")

The generalised, impersonal "you" above co-occurs with other linguistic phenomena that present general information - the generic present tense, expressions such as "whatever" and "all" (Stirling \& Manderson, 2011). In other words, it connects to "the grammar of genericity" (Stirling \& Manderson, 2011: 1584). As no other addressivity strategies in the instances of Journey metaphor use were identified in professional blogs, preference for the impersonal "you" can be tentatively interpreted through Stirling and Manderson's (2011) suggestion that the impersonal "you" has the function of displaying distance and objectivity attributes associated with professionalism. The use of this addressivity strategy can thus, be linked to medical experts' efforts for self-presentation as professional and objective sources of knowledge and advice on a "front stage" platform.

\subsection{Conclusions, limitations, future directions}

This study examined obesity blogs authored by individuals and medical experts which have been little researched. It also explored aspects of obesity blogging that have been particularly understudied: (1) the conceptualisation of the overall obesity experience via metaphors and (2) 
the addressivity devices employed by bloggers in the instances of metaphor use. It additionally showed how the analysis of metaphor and addressivity in blogs can shed light on selfpresentation.

A key finding of this study was that in contrast to mainstream obesity narratives, particularly in the news media, it was Journey and not War that emerged as the most productive source domain to discuss obesity. This can be seen as affirmation of the potential of blogs to offer a space where alternative to the mainstream narratives can surface. Journeys are a potent source domain for metaphor because of the availability of a clear schema that includes "required elements" such as start and end points connected by a path and entities that move along the path (Charteris-Black, 2011: 66). It is also rich in "optional elements" that may include (much like the examples from this study) the speed of travel, the length of the journey, travel guides and companions (Charteris-Black, 2011: 66). If the required elements are "so much part of our experience that we are barely conscious of them," the optional elements serve as "a rich basis for inferential reasoning and evaluation" (Charteris-Black, 2011: 67).

The ways in which such optional elements were recruited suggest that both individuals and medical experts saw obesity and weight loss as far from straightforward. This view contrasts the mainstream before-after weight loss narrative. By discussing short and long, fast and slow, lone and accompanied journeys, individuals highlighted the fact that there is no onesize-fits-all solution to obesity that works for everyone. In both personal and professional blogs, the importance of perseverance and maintaining forward movement was emphasised and setbacks along the way were seen as much less of a failure than what the mainstream War metaphor may have suggested. By presenting the obesity experience in these ways, the analysed blogs reworked mainstream narratives and added a voice that is lacking in mainstream representations of obesity. One limitation of this study though is that it did not analyse readers' comments to posts and consequently, cannot comment whether Journey metaphors used in the posts were picked up by readers and if so, how they were evaluated.

If personal and professional blogs converged in employing Journey metaphors to challenge the mainstream before-after weight loss narrative, differences emerged with respect to use of addressivity strategies. Individuals used a range of addressivity devices (the pronoun "you," questions, directives) and often mixed them. When using the pronoun "you," individuals oriented to the audience of the blog or a sub-group of their readership. As their posts are based around personal experiences, it is not unexpected that they oriented in this way and addressed others who may have had (or are currently having) a similar experience. Medical experts, in contrast, preferred the impersonal "you" which helps project distance and objectivity and consequently, professionalism.

Overall, this study demonstrated the value of obesity blogs as a platform where more nuanced narratives that present an alternative to the mainstream may surface. It showed how bloggers recruited Journey metaphors to conceptualise different aspects of obesity - with the limitation that readers' reactions to such metaphor use were not tracked. Instead of commenting, interactivity here was analysed in terms of the addressivity devices that bloggers used to make readers feel talked to. The study also demonstrated how critical metaphor analysis and addressivity analysis can be combined to probe the complexity of self-presentation on obesity blogs. Alongside these contributions, another limitation is that the analysed blogs were not a scientifically designed random sample. The findings should therefore be read with caution in terms of generalisability. Finally, as the analysed blogs were all North American (US and Canadian), there is a need for future research to examine the interplay of culture, metaphor and addressivity in blog discussions of obesity.

\section{Acknowledgements}

Thanks to the two referees and the Special Issue Editors for their help and guidance. 


\section{Funding sources}

This research did not receive any specific grant from funding agencies in the public, commercial, or not-for-profit sectors.

\section{Conflicts of interest}

None.

\section{References}

Archibald D, Douglas F, Hoddinott P, van Teijlingen E, Stewart F, Robertson C, Boyers D \& Avenell A (2015) A qualitative evidence synthesis on the management of male obesity. BMJ Open, DOI: 10.1136/bmjopen-2015-008372.

Ata R N \& Thompson K J (2010) Weight bias in the media: A review of recent research. Obesity Facts 3: 41-46.

Atanasova D \& Koteyko N (2016) Obesity frames and counter-frames in British and German online newspapers. Health 21(6): 650-669, https://doi.org/10.1177/1363459316649764.

Blaine B \& McElroy J (2002) Selling stereotypes: Weight loss infomercials, sexism, and weightism. Sex Roles 46: 351-357.

Bronstein J (2013) Personal blogs as online presences on the internet: Exploring selfpresentation and self-disclosure in blogging. Aslib Proceedings: New Information Perspectives 65(2): 161-181.

Cameron L (2016) Mixed metaphors from a discourse dynamics perspective: A non-issue? In Gibbs R W Jr (ed) Mixing metaphor, Amsterdam: John Benjamins, pp. 17-30.

Charteris-Black J (2004) Corpus approaches to critical metaphor analysis. Basingstoke and New York, NY: Palgrave-MacMillan.

Charteris-Black J (2011) Politicians and rhetoric: The persuasive power of metaphor $2^{\text {nd }}$ edition. New York, NY: Palgrave-MacMillan.

De Brún A, McKenzie K, McCarthy M \& McGloin A (2012) The emergence and portrayal of obesity in The Irish Times: Content analysis of obesity coverage, 1997-2009. Health Communication 27(4): 389-398.

Demjen Z, Semino E \& Koller V (2016) Metaphors for 'good' and 'bad' deaths: A health professional view. Metaphor and the Social World 6(1): 1-19.

Eastham L A (2011) Research using blogs for data: Public documents or private musings? Research in Nursing \& Health, 34: 353-361.

Fikkan J L \& Rothblum E D (2012) Is fat a feminist issue? Exploring the gendered nature of weight bias. Sex Roles 66: 575-592.

Fuchs H F, Broderick R C, Harnsberger C R, Chang D C, Sandler B J, Jacobsen G R \& Horgan S (2015) Benefits of bariatric surgery do not reach obese men. Journal of Laparoendoscopic \& Advanced Surgical Techniques 25(3): 196-201.

Geier A B, Schwartz M B \& Brownell K D (2003) "Before and After" diet advertisements escalate weight stigma. Eating and Weight Disorders 8: 282-288.

Greenland K (2013) Negotiating self-presentation, identity, ethics, readership and privacy in the LIS blogosphere: A review of the literature. Australian Academic \& Research Libraries 44(4): 217-225.

Gregoriou C (2011) Language, Ideology and Identity in Serial Killer Narratives. New York: Routledge.

Goffman E (1959) The presentation of self in everyday life. New York: Anchor Books. 
Heatherton T F, Mahamedi F, Striepe M, Field A E \& Keel P (1997) A 10-year longitudinal study of body weight, dieting, and eating disorder symptoms. Journal of Abnormal Psychology 106: 117-125.

Hellsten I (2008) Popular metaphors of biosciences: Bridges over time? Configurations 16(1): 11-32.

Herring S C, Kouper I, Scheidt L A \& Wright E (2004) Women and children last: the discourse construction of weblogs In Gurak L, Antonijevic S, Johnson L A, Ratliff C \& Reyman J (eds) Into the blogosphere: Rhetoric, community, and culture of weblogs. Minneapolis: University of Minnesota, pp. 1-16.

Hogan B (2010) The presentation of self in the age of social media: Distinguishing performances and exhibitions online. Bulletin of Science Technology \& Society 30: $377-386$.

Hookway N (2008) 'Entering the blogosphere': Some strategies for using blogs in social research. Qualitative Research 8(1): 91-113.

Jaborooty M P \& Baker P (2017) Resisting silence: Moments of empowerment in Iranian women's blogs. Gender \& Language 11(1): 77-99.

Karlsson L (2007) Desperately seeking sameness: The processes and pleasures of identification in women's diary blog readings. Feminist Media Studies, DOI: 10.1080/14680770701287019.

Koteyko N \& Hunt D (2016) Performing health identities on social media: An online observation of Facebook profiles. Discourse, Context and Media 12: 59-67.

Leggatt-Cook C \& Chamberlain K (2012) Blogging for weight loss: Personal accountability, writing selves, and the weight-loss blogosphere. Sociology of Health \& Illness 34(7): 963-977.

Levy-Navarro E (2009) Fattening queer history: Where does fat history go from here? In Rothblum E D \& Solovay S (eds) The fat studies reader, New York \& London: New York University Press, pp. 15-25.

Lingetun L, Fungbrant M, Claesson I \& Baggens C (2017) 'I just want to be normal' - A qualitative study of pregnant women's blogs who present themselves as overweight or obese. Midwifery 49: 65-71.

Lomborg S (2014) Social media, social genres: Making sense of the ordinary. New York: Routledge.

Maor M (2014) Stories that matter: subverting the before-and-after weight loss narrative. Social Semiotics, DOI: 10.1080/10350330.2013.827359.

Myers G (2010a) The discourse of blogs and Wikis. London: Continuum.

Myers G (2010b) Stance-taking and public discussion in blogs. Critical Discourse Studies 7(4): 263-275.

Myers G \& Lampropoulou S (2012) Impersonal you and stance-taking in social research interviews. Journal of Pragmatics 44: 1206-1218.

Nilsson B (2012) Politicians' blogs: Strategic self-presentations and identities. Identity 12(3): 247-265

Page R E (2012) Stories and social media: Identities and interactions. New York and London: Routledge.

Pew Research Center (2014) The social life of health information, Available at http://www.pewresearch.org/fact-tank/2014/01/15/the-social-life-of-healthinformation/ (Accessed 31 March 2017).

Pragglejaz Group (2007) A method for identifying metaphorically used words in discourse. Metaphor Symbol 22: 1-39.

Puhl R M \& Heuer C A (2009) The stigma of obesity: A review and update. Obesity 17(5): 941-964. 
Reisebrodt M (2010) The promise of salvation: A theory of religion. Chicago: University of Chicago Press.

Ritchie L D (2013) Metaphor. Cambridge \& New York: Cambridge University Press.

Roush W (2011) Healthline battles WebMD with personalized medical search tools, body maps, Available at: http://www.xconomy.com/san-francisco/2011/11/30/healthlinebattles-webmd-with-personalized-medical-search-tools-and-3d-body-maps/\# (Accessed 11 April 2016).

Rowse D (2005) What is a blog? Available at: https://problogger.com/what-is-a-blog/ (Accessed 10 September 2017).

Saguy A C \& Almeling R (2008) Fat in the fire? Science, the news media, and the 'obesity epidemic'. Sociological Forum 23(1): 53-83.

Schaefer A (2016) The 14 best obesity blogs of 2016. Available at: http://www.healthline.com/health/best-obesity-blogs-of-the-year (accessed 23 December 2016).

Seale C, Ziebland S \& Charteris-Black J (2006) Gender, cancer experience and internet use: A comparative keyword analysis of interviews and online cancer support groups. Social Science and Medicine 62(10): 2577-2590.

Semino E (2008) Metaphor in discourse. Cambridge: Cambridge University Press.

Semino E, Demjén Z, Demmen J, Koller V, Payne S, Hardie A \& Rayson P (2015) The online use of Violence and Journey metaphors by patients with cancer, as compared with health professionals: A mixed methods study. BMJ Supportive and Palliative Care 1-7.

Stirling L \& Manderson L (2011) About you: Empathy, objectivity and authority. Journal of Pragmatics 43: 1581-1602.

Tay D (2011) Therapy is a journey as a discourse metaphor. Discourse Studies 13(1): 47-68.

World Health Organization (2016) Obesity and overweight. Available at: http://www.who.int/mediacentre/factsheets/fs311/en/ (Accessed 31 March 2017). 